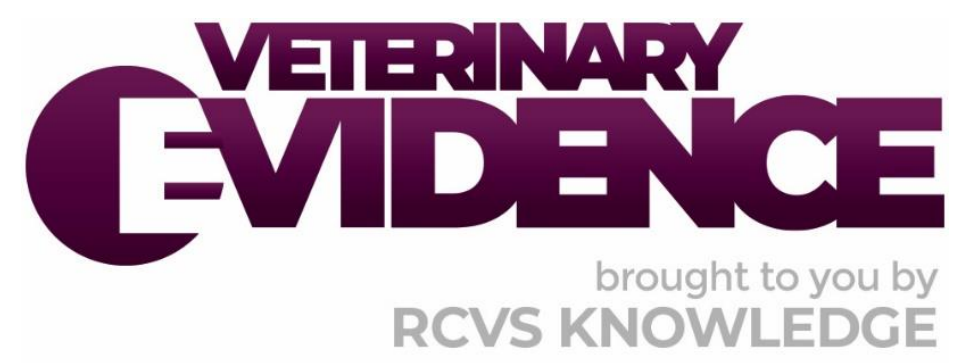

\title{
The Use of Ultrasonography for Detection of Meniscal Damage in Dogs
}

\author{
A Knowledge Summary by
}

Peter Coss BVSc, MRCVS ${ }^{1 *}$

${ }^{1}$ Langford Vets, University of Bristol, Langford, BS40 5DU
${ }^{*}$ Corresponding Author (pc17258@my.bristol.ac.uk)

ISSN: 2396-9776

Published: 11 Jun 2019

in: Vol 4, Issue 2

DOI: http://dx.doi.org/10.18849/ve.v4i2.207

Reviewed by: Nina Kieves (DVM, DACVS-SA, DACVSMR, CCRT) and Wye Chong (BVSc, MANZCVS) and Matt Brunke (DVM, DACVSMR, CCRP, CVPP, CVA)

Next Review Date: May 21st 2020 


\section{KNOWLEDGE SUMMARY}

\section{PICO question}

In dogs, what is the sensitivity and specificity of using ultrasound as a diagnostic test to identify meniscal damage?

\section{Clinical bottom line}

Although there are limited studies assessing the accuracy of ultrasound for detecting meniscal damage, it appears to be a potentially useful diagnostic test with reported sensitivity varying from $82-95 \%$ and specificity from $82-93 \%$ when compared to arthroscopy or arthrotomy findings. Experience of the ultrasonographer is also likely to be an important factor to consider.

\section{Clinical Scenario}

In dogs which have clinically suspected stifle or meniscal pathology, surgical arthrotomy or arthroscopy is often used to evaluate (and treat if indicated) meniscal disease. In those dogs without meniscal pathology, this surgical exploration could be avoided (provided there are no other indications for surgical intervention) if a noninvasive, alternative test could be used. Ultrasonography of the menisci is well described, however, this is not currently widely utilised as a diagnostic test. Given the potential use of ultrasound for this purpose, it is important to know the accuracy of its use as a test for meniscal damage, more precisely the sensitivity and specificity.

\section{Summary of the evidence}

\begin{tabular}{|c|c|}
\hline \multicolumn{2}{|l|}{ Arnault et al. (2009) } \\
\hline \multicolumn{2}{|r|}{$\begin{array}{l}\text { Dogs with clinically suspected partial or complete cranial cruciate } \\
\text { ligament rupture }\end{array}$} \\
\hline Sample size: & 13 dogs \\
\hline Intervention details: & $\begin{array}{l}\text { - Ultrasound performed within } 2 \text { days prior to arthrotomy. } \\
\text { - }-16 \mathrm{MHz} \text { linear transducer used by experienced } \\
\text { ultrasonographers. } \\
\text { - } \text { Examination of menisci was performed in three longitudinal } \\
\text { approaches. } \\
\text { - Other views were performed to image other aspects of the } \\
\text { stifle. } \\
\text { - At arthrotomy, surgeons recorded a visual assessment of the } \\
\text { joint. They were blinded to the ultrasound findings. }\end{array}$ \\
\hline Study design: & Prospective, cross sectional study \\
\hline Outcome studied: & $\begin{array}{l}\text { Sensitivity, specificity, positive and negative predictive } \\
\text { values of ultrasonography for detection of meniscal lesions } \\
\text { and of meniscal clicking as a sign of a meniscal tear. }\end{array}$ \\
\hline
\end{tabular}




\begin{tabular}{|c|c|}
\hline & $\begin{array}{l}\text { - Diagnostic accuracy of cranial cruciate ligament rupture } \\
\text { diagnosed by ultrasound. } \\
\text { - Correlation of ultrasonographic vs. surgical osteophyte score } \\
\text { (method of scoring not explained). }\end{array}$ \\
\hline $\begin{array}{l}\text { Main findings: } \\
\text { (relevant to PICO question): }\end{array}$ & $\begin{array}{l}\text { Sensitivity, specificity, positive and negative predictive values of } \\
\text { ultrasonography for detection of meniscal lesions were } 82 \%, 93 \% \text {, } \\
90 \% \text { and } 88 \% \text { respectively. }\end{array}$ \\
\hline Limitations: & $\begin{array}{l}\text { - Small sample size. } \\
\text { - } \quad \text { Aack of normal controls. } \\
\text { ligament rupture so were not a normal population. } \\
\text { - } \quad \text { Arthrotomy used as gold standard comparison however } \\
\text { arthroscopy would have been more sensitive. } \\
\text { - Some meniscal lesions may have been missed at surgery due } \\
\text { to using only a craniolateral approach for arthrotomy. } \\
\text { - Surgeons were blinded to imaging results but not to clinical } \\
\text { examination findings. }\end{array}$ \\
\hline
\end{tabular}

Franklin et al. (2017)

\begin{tabular}{|c|c|}
\hline Population: & $\begin{array}{l}\text { Dogs with clinically suspected partial or complete cranial cruciate } \\
\text { ligament rupture }\end{array}$ \\
\hline Sample size: & 26 dogs \\
\hline Intervention details: & $\begin{array}{l}\text { - } \quad \text { Orthopaedic examination was performed. } \\
\text { - } \text { reviewed by a blinded radiologist. } \\
\text { - } 5 \text { 5-18 MHz linear array probe was used by one surgeon to } \\
\text { conduct an ultrasound examination evaluating cranial, } \\
\text { middle and caudal aspects of the medial meniscus. Menisci } \\
\text { were graded on the ultrasound findings. } \\
\text { - } \quad \text { Arthroscopy was then performed. } \\
\text { - Surgical treatment for cranial cruciate rupture/meniscal } \\
\text { - damage was performed as necessary. } \\
\text { The arthroscopy was recorded and then reviewed } \\
\text { retrospectively by the operating surgeon and another } \\
\text { surgeon working independently, who was blinded to all } \\
\text { other results. } \\
\text { Meniscal lesions were graded as surgical or not across } \\
\text { ultrasound, arthroscopy and MRI examinations. }\end{array}$ \\
\hline Study design: & Prospective, cross sectional study \\
\hline Outcome studied: & $\begin{array}{l}\text { Sensitivity, specificity and correct classification rate for detection of } \\
\text { surgical medial meniscal disease of meniscal click, pain on flexion, } \\
\text { ultrasound and MRI findings compared to arthroscopy }\end{array}$ \\
\hline $\begin{array}{l}\text { Main findings: } \\
\text { (relevant to PICO question): }\end{array}$ & $\begin{array}{l}\text { Sensitivity and specificity for detection of surgical medial meniscal } \\
\text { disease using ultrasound was } 95 \% \text { and } 82 \% \text { respectively when } \\
\text { compared to arthroscopy findings. Sensitivity and specificity data } \\
\text { was based on: }\end{array}$ \\
\hline
\end{tabular}




\begin{tabular}{|c|c|}
\hline & $\begin{array}{l}\text { - Correct detection of surgical disease in } 19 / 20 \text { stifles for } \\
\text { surgeon one. } \\
\text { - Correct categorisation as non-surgical menisci in } 9 / 11 \text { stifles } \\
\text { for surgeon one. } \\
\text { - Correct detection of surgical disease in } 19 / 20 \text { stifles for } \\
\text { surgeon two. } \\
\text { - Correct categorisation as non-surgical menisci in } 7 / 11 \text { stifles } \\
\text { for surgeon two. }\end{array}$ \\
\hline Limitations: & $\begin{array}{l}\text { - Small study size. } \\
\text { - } \quad \text { Medial menisci assessed only. } \\
\text { - The main surgeon had limited experience with } \\
\text { ultrasonography of the stifle and was not blinded to the } \\
\text { physical examination findings. } \\
\text { - The same surgeon that performed the ultrasound performed } \\
\text { the arthroscopies so was not blinded. } \\
\text { Criteria for surgical vs. non-surgical lesions was defined for } \\
\text { the study there are no references for the basis of this } \\
\text { criteria. }\end{array}$ \\
\hline
\end{tabular}

\begin{tabular}{|c|c|}
\hline \\
\hline \multicolumn{2}{|r|}{$\begin{array}{l}\text { Dogs admitted for evaluation of joint disease localised to the stifle. } \\
\text { They also had to have a presumptive clinical diagnosis of meniscal } \\
\text { pathology, an ultrasound examination and arthroscopy of the } \\
\text { affected joint. }\end{array}$} \\
\hline Sample size: & 12 joints across 10 dogs \\
\hline Intervention details: & $\begin{array}{l}\text { - Ultrasound was performed using a } 12-14 \mathrm{MHz} \text { probe by a } \\
\text { blinded ultrasonographer. } \\
\text { - Imaging of the medial and lateral menisci were performed in } \\
\text { three regions: cranial, middle and caudal. } \\
\text { - Arthroscopy was performed within } 48 \mathrm{hrs} \text { of the ultrasound } \\
\text { by one surgeon blinded to the ultrasound results. A retractor } \\
\text { was used through a separate portal in some dogs to } \\
\text { maximise visualisation of the menisci. } \\
\text { - Any abnormalities were recorded and surgical treatment } \\
\text { was carried out as felt necessary by the surgeon. } \\
\text { Data from the two diagnostic methods were compared by } \\
\text { two investigators using the arthroscopy results as the gold } \\
\text { standard. }\end{array}$ \\
\hline Study design: & Prospective cross sectional study \\
\hline Outcome studied: & $\begin{array}{l}\text { Sensitivity, specificity, positive and negative predictive values of } \\
\text { ultrasound for meniscal lesions when compared to arthroscopy } \\
\text { findings }\end{array}$ \\
\hline $\begin{array}{l}\text { Main findings: } \\
\text { (relevant to PICO question): }\end{array}$ & $\begin{array}{l}\text { Sensitivity, specificity, positive and negative predictive values of } \\
\text { ultrasound for meniscal lesions when compared to arthroscopy } \\
\text { findings were } 90.0 \%, 90.2 \%, 90.0 \% \text { and } 92.9 \% \text { respectively }\end{array}$ \\
\hline
\end{tabular}




\begin{tabular}{|l|l|}
\hline Limitations: & $\begin{array}{l}\text { - Small study size. } \\
\end{array}$ \\
& $\begin{array}{l}\text { - Lack of normal controls. } \\
\text { - Arthroscopy surgeon not blinded to clinical findings. }\end{array}$ \\
& $\begin{array}{l}\text { - Experience of ultrasonographer not commented on so is } \\
\text { unknown. }\end{array}$ \\
\hline
\end{tabular}

\section{Appraisal, application and reflection}

The original literature search revealed that there are several examples in the literature and books detailing how to perform an examination of the menisci however there were only three papers which assess this for suitability as a diagnostic test by evaluating sensitivity and specificity.

All papers were prospective cross sectional studies however, and used small numbers of dogs. The population across all three papers consisted of dogs with clinically suspected stifle disease or cranial cruciate ligament rupture and there were no normal dogs available as control subjects in any paper.

Arnault et al. (2009) assessed the use of ultrasound for general stifle lesions against arthrotomy findings. They reported a sensitivity and specificity of $82 \%$ and $93 \%$ respectively for ultrasonography in the detection of meniscal lesions by experienced ultrasonographers. One limitation of this study when compared to the others is that arthrotomy was used as the gold standard test. Within the discussion the authors comment on and reference the point that arthroscopy is more sensitive and hence would have made for a more suitable gold standard comparison. They also comment further that some meniscal lesions may have been missed at surgery due to their use of solely a craniolateral approach to arthrotomy, which may not allow visualisation of the entire meniscal surfaces. The study was partially blinded in that the imaging results were unknown to the surgeon although there would likely be some degree of bias because the surgeons were aware of the history and clinical examination findings of the dogs.

Franklin et al. (2017) investigated the use of stifle ultrasonography and also MRI for detection of surgical medial meniscal lesions when compared to arthroscopic findings. They reported a sensitivity and specificity of $95 \%$ and $82 \%$ respectively for ultrasonography in detection of medial meniscal lesions. One flaw in this study was that a surgeon with limited experience of stifle ultrasonography performed the ultrasound examinations. The same surgeon that performed the ultrasound also performed the arthroscopy afterwards and so could be biased with regard to the results. The statistics in this study were performed on the basis of whether a meniscus was surgical rather than if any lesion was present. The specific list of pathological changes which constituted a surgical or non-surgical meniscus was created for this study rather than being based on specific literature, so it may not be directly comparable across studies. Only medial menisci were evaluated in this study, likely because of the majority of meniscal disease to be medial, however it would have been ideal to include both menisci to increase overall number of menisci scanned in the study and to assess for differences in scanning difficulty or findings.

Mahn et al. (2005) also evaluated ultrasound as a diagnostic test as compared to arthroscopic findings. They reported a sensitivity and specificity of $90 \%$ and $90.2 \%$ respectively for ultrasonography in the detection of meniscal lesions. The surgeon for the arthroscopy was not blinded to the clinical findings so there may be some bias, as seen in the other papers. The experience of the ultrasonographer in this paper was not commented on so is unknown. During the arthroscopy an extra retractor was utilised through a separate port when necessary to maximise visualisation of the menisci which could have aided in lesion detection when compared to the use of a standard arthroscopy technique.

Overall the reported sensitivity varies from $82-95 \%$ and specificity from $82-93 \%$. All three papers used high frequency probes for the assessment, which is likely to be an important prerequisite for general lesion identification. They also used cranial, middle and caudal views together for full assessment of the menisci. Two of the papers (Arnault et al., 2009; Franklin et al., 2017) comment on the difficulty involved with stifle ultrasonography and interpretation, therefore the sensitivity and specificity of using ultrasound as a diagnostic 
test for meniscal damage is likely to be heavily reliant on the experience of the ultrasonographer.

In summary, although there are few studies evaluating the subject, the use of ultrasound for identification of meniscal lesions appears to have good sensitivity and specificity in populations of dogs with suspected stifle disease. It is likely to be a useful diagnostic test however experience of the ultrasonographer may be an important factor to consider.

\section{Methodology Section}

\begin{tabular}{|r|l|}
\hline \multicolumn{2}{|l|}{ Search Strategy } \\
\hline $\begin{array}{r}\text { Databases searched and dates } \\
\text { covered: }\end{array}$ & $\begin{array}{l}\text { CAB Abstracts via the Ovid platform, covering from } 1973 \text { to } 2018 \\
\text { Week 19. } \\
\text { Medline via the Ovid platform, covering from } 1946 \text { to } 2018 .\end{array}$ \\
\hline Search terms: & $\begin{array}{l}\text { (Dog* OR bitch* OR canine*) AND (menisc* OR stifle) AND (ultra*) } \\
\text { AND (damage* OR lesion* OR trauma* OR tear OR injur* OR } \\
\text { pathol*) }\end{array}$ \\
\hline Dates searches performed: & $21 / 05 / 2018$ \\
\hline
\end{tabular}

\section{Exclusion / Inclusion Criteria}

Exclusion: Articles not available in English, single case reports, book chapters, conference proceedings, articles which did not answer the PICO question and literature reviews.

Inclusion: Articles available in English which were relevant to the PICO. Articles had to involve more than one animal.

Please add rows as necessary

\begin{tabular}{|c|c|c|c|c|c|c|}
\hline Database & $\begin{array}{l}\text { Number } \\
\text { of } \\
\text { results }\end{array}$ & $\begin{array}{l}\text { Excluded } \\
\text { - did not } \\
\text { answer } \\
\text { the PICO }\end{array}$ & $\begin{array}{l}\text { Excluded - not } \\
\text { in English }\end{array}$ & $\begin{array}{l}\text { Excluded - } \\
\text { irrelevant to } \\
\text { PICO }\end{array}$ & $\begin{array}{c}\text { Excluded - } \\
\text { Conference } \\
\text { Paper/Book/Review }\end{array}$ & $\begin{array}{l}\text { Total } \\
\text { relevant } \\
\text { papers }\end{array}$ \\
\hline $\begin{array}{l}\text { CAB } \\
\text { Abstracts }\end{array}$ & 34 & 7 & 9 & 9 & 7 & 2 \\
\hline Medline & 25 & 3 & 5 & 13 & 1 & 3 \\
\hline \multicolumn{6}{|c|}{ Total relevant papers when duplicates removed } & 3 \\
\hline
\end{tabular}


The author declares no conflicts of interest.

\section{REFERENCES}

1. Arnault, F., Cauvin, E., Viguier, E., Kraft, E., Sonet, J., and Carozzo, C. (2009) 'Diagnostic value of ultrasonography to assess stifle lesions in dogs after cranial cruciate ligament rupture: 13 cases', Veterinary and Comparative Orthopaedics and Traumatology, 22(6), pp. 479-485. DOI: 10.3415/VCOT08-10-0103.

2. Franklin, S.P., Cook, J.L., Cook, C.R., Shaikh, L.S., Clarke, K.M., and Holmes, S.P. (2017) 'Comparison of ultrasonography and magnetic resonance imaging to arthroscopy for diagnosing medial meniscal lesions in dogs with cranial cruciate ligament deficiency', Journal of the American Veterinary Medical Association, 251(1), pp. 71-79. DOI: https://doi.org/10.2460/javma.251.1.71.

3. Mahn, M.M., Cook, J.L., Cook, C.R., and Balke, M.T. (2005) 'Arthroscopic verification of ultrasonographic diagnosis of meniscal pathology in dogs', Veterinary Surgery, 34(4), pp. 318-323. DOI: https://doi.org/10.1111/i.1532-950X.2005.00049.x. 


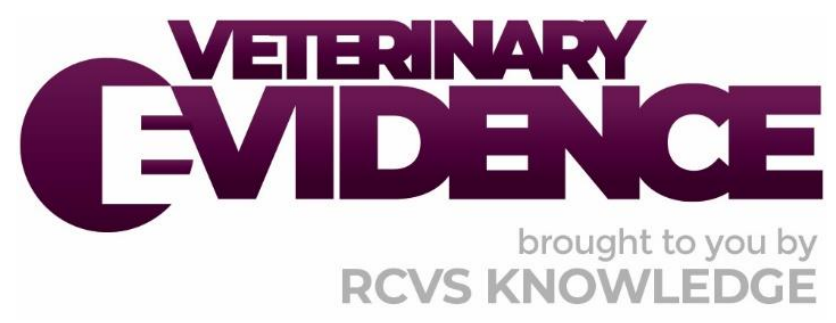

\section{Intellectual Property Rights}

Authors of Knowledge Summaries submitted to RCVS Knowledge for publication will retain copyright in their work, and will be required to grant RCVS Knowledge a non-exclusive license of the rights of copyright in the materials including but not limited to the right to publish, re-

publish, transmit, sell, distribute and otherwise use the materials in all languages and all media throughout the world, and to license or permit others to do so.

\section{Disclaimer}

Knowledge Summaries are a peer-reviewed article type which aims to answer a clinical question based on the best available current evidence. It does not override the responsibility

of the practitioner. Informed decisions should be made by considering such factors as individual clinical expertise and judgement along with patient's circumstances and owners' values. Knowledge Summaries are a resource to help inform and any opinions expressed within the Knowledge Summaries are the author's own and do not necessarily reflect the view of the RCVS Knowledge. Authors are responsible for the accuracy of the content. While the

Editor and Publisher believe that all content herein are in accord with current recommendations and practice at the time of publication, they accept no legal responsibility

for any errors or omissions, and make no warranty, express or implied, with respect to material contained within.

For further information please refer to our Terms of Use.

RCVS Knowledge is the independent charity associated with the Royal College of Veterinary Surgeons (RCVS). Our ambition is to become a global intermediary for evidence based veterinary knowledge by providing access to information that is of immediate value to practicing veterinary professionals and directly contributes to evidence based clinical decision-making.

https://www.veterinaryevidence.org/

RCVS Knowledge is a registered Charity No. 230886.

Registered as a Company limited by guarantee in England and Wales No. 598443.

Registered Office: Belgravia House, 62-64 Horseferry Road, London SW1P 2AF

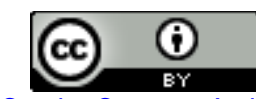

This work is licensed under a Creative Commons Attribution 4.0 International License 